\title{
Osteoporosis Knowledge Among Spine Surgery Patients
}

\author{
CHARLA R. FISCHER, MD, ${ }^{1}$ ESHAN VASUDEVA, BS, ${ }^{2}$ BRYAN BEAUBRUN, BS, ${ }^{1}$ \\ ZACHARY MESSER, BS, ${ }^{2}$ ALEJANDRO CAZZULLINO, BS, ${ }^{2}$ RONALD LEHMAN, MD $^{2}$ \\ ${ }^{I}$ NYU Langone Orthopedic Hospital, Department of Orthopedic Surgery, New York, New York, ${ }^{2}$ Columbia University Medical Center, Department of Orthopedic \\ Surgery, New York, New York
}

\begin{abstract}
Background: The purpose of this study is to evaluate the knowledge and attitudes on osteoporosis among firsttime spine surgery patients.

Methods: An electronic survey consisting of demographics, prior experience with osteoporosis, and the Facts on Osteoporosis Quiz (FOOQ) was sent via email to first-time spine surgery patients. Patients were then randomized into 2 groups: 1 received a brief osteoporosis information packet prior to beginning the FOOQ, and 1 proceeded directly to the survey.

Results: A total of 63 patients who participated in this study, 29 in the information packet group and 34 in the non-information packet group, completed the survey. The mean FOOQ scores for the information packet patients was $16.37( \pm 2.35)$ and for the non-information packet patients was $15.62( \pm 2.87)$, with a $P$ value of .12 . There were no statistically significant differences between the 2 groups in terms of patient demographics or prior experience with osteoporosis. The information packet group trended to higher interest with a $P$ value of .068 .

Conclusions: Our study demonstrates high FOOQ scores among all first-time spine patients as compared to historical scores in general at-risk populations. No statistical differences between FOOQ scores were noted between the group that received the information packet and the control group. This study demonstrates that patients new to spine care have a good understanding of osteoporosis and are thus willing to participate in osteoporosis treatment as part of their spine care.
\end{abstract}

Other and Special Categories

Keywords: bone density, osteoporosis, patient education

\section{INTRODUCTION}

Surgical interventions on the spine are among the most common orthopedic procedures being performed in the United States, with more than 250000 spinal fusions done each year. ${ }^{1}$ Studies have shown that among patients undergoing lumbar spinal fusions, $51.3 \%$ of women and $14.5 \%$ of men also have osteoporosis. ${ }^{2}$ Spinal fusion surgery involves instrumentation into bone as well as incorporation of bone grafts into existing bone tissue, and, as such, low bone mineral density is related to poorer outcomes. ${ }^{3-7}$

Patients with osteoporosis undergoing spinal instrumentation are at higher risk for complications, including vertebral fractures, pedicle fractures, pseudarthrosis, proximal junctional kyphosis, and loosening of pedicle screws. ${ }^{3-7}$ Patients with poor bone quality have been noted to have higher rates of early complications following instrumentation, with Dewald and Stan- ley $y^{3}$ noting in 2006 a $13 \%$ rate of compression or pedicle screw fractures in osteoporotic patients requiring surgical revision in a single-center cohort. This same cohort also had increased rates of late surgical complications, including higher rates of pseudarthrosis and pedicle screw loosening. ${ }^{7}$ The risk of pedicle screw loosening has also been evaluated in cadaveric models and was shown to be strongly correlated with bone mineral density. ${ }^{4}$

While the effects of poor bone quality on spinal instrumentation outcomes is well documented, current consensus regarding the perioperative treatment of osteoporosis for spinal fusion patients continues to evolve. Initial studies have noted faster and higher rates of bone union in patients treated with osteoporotic regimens; postsurgical treatment with recombinant human parathyroid hormone in particular continues to attract investigative attention. Initial studies in animal spinal fusion models demonstrated increased bone re- 
modeling and improved microstructural parameters in rabbits and rats undergoing postsurgical treatment with teriparatide. ${ }^{5,7}$ One recent study has shown that teriparatide treatment after lumbar spinal fusion in postmenopausal women with osteoporosis results in lower rates of pedicle screw loosening $(7 \%-13 \%$ as compared to $15 \%-25 \%$ in the bisphosphonate group), suggesting that treating osteoporosis in the postsurgical setting results in superior outcomes. ${ }^{6}$

As such, osteoporosis and perioperative treatment have important implications for spine surgery outcomes and should be an important consideration for any patient desiring spinal fusion surgery. Additionally, osteoporosis incidence continues to grow as life expectancy increases; current estimates report that over 10 million US adults over the age of 50 suffer from osteoporosis, with an expected increase to 14 million by $2020 .^{8}$ However, despite increasing incidence, osteoporosis remains an undertreated condition with only $20 \%$ of patients with hip or fragility fractures receiving medication for osteoporosis. ${ }^{9}$

Our study aimed to evaluate the level of knowledge of osteoporosis among patients presenting to spine clinic for initial surgical evaluation.

Given the high incidence of osteoporosis and the potentially pivotal role an orthopedic surgeon can play in initiating osteoporosis treatment, it is important to understand the baseline knowledge on osteoporosis of the typical first-time spine patient. Evaluating patient osteoporosis knowledge will allow us to better understand whether patients need further education regarding osteoporosis and possibly what the best setting might be for this education. It is also important from a surgical perspective for patients to specifically understand that low bone mineral density may be associated with poorer surgical outcomes.

We also aimed to evaluate the use of a simple information packet, published by the International Foundation for Osteoporosis, in improving osteoporosis-related knowledge among participants. Such an instrument could present a cost-effective, easily reproducible method to help orthopedic providers improve patient knowledge regarding osteoporosis.

\section{MATERIALS AND METHODS}

After obtaining institutional review board approval, this study surveyed patients visiting an orthopedic spine surgeon for the first time in a large multiprovider academic spine hospital. Firsttime patients were asked by their spine surgeons if they would be interested in taking a survey about osteoporosis. Survey links were then emailed to patients. As an incentive to participate, all survey respondents were offered a $\$ 10$ electronic gift card in exchange for their participation. By clicking on the link, patients were able to complete the survey on an Internet-enabled device of their choosing. Our survey included detailed patient demographic data, prior experience with osteoporosis, and interest in pursuing osteoporosis treatment. After the survey, the patients took the Facts on Osteoporosis Quiz (FOOQ) to assess their knowledge of osteoporosis.

The FOOQ is a validated survey instrument used to evaluate patients' knowledge of osteoporosis. The quiz consists of 20 true-or-false questions concerning osteoporosis epidemiology, risk factors, prevention, and treatment. The FOOQ was first developed in $1998^{10}$ and has been continually updated to reflect current National Institutes of Health consensus statements on the scientific evidence regarding osteoporosis. $^{11}$

Patients who elected to participate were randomly divided into 2 groups. The first group underwent patient education intervention prior to taking the survey and the FOOQ. The patient was provided with an information packet with simple information about osteoporosis and how it can affect their health. The information packet consisted of images and illustration published by the International Osteoporosis Foundation and provided basic information about bone health and osteoporosis (Supplemental Appendix: http:// www.ijssurgery.com/lookup/suppl/doi:10.14444/ 5086/-/DC1/ijss-12-06-06_s01.pdf). Approval to use the information packet was obtained by from the International Osteoporosis Foundation. The packet was embedded into the survey and accessible on any Internet-enabled device, including smartphones, tablets, and computers. Patients were free to peruse the packet as long as they felt necessary. They were then directed to the survey and then the FOOQ. The nonintervention group of patients were not given the information packet. They were directed to the survey immediately and then the FOOQ. All data were downloaded to our institutional secured and encrypted network for further analysis. A power analysis was performed 
Table 1. Patient characteristics.

\begin{tabular}{|c|c|c|c|c|c|}
\hline & $\begin{array}{c}\text { No } \\
\text { Packet, \% }\end{array}$ & n & $\begin{array}{c}\text { Packet, } \\
\%\end{array}$ & $\mathbf{n}$ & $\begin{array}{c}P \\
\text { Value }\end{array}$ \\
\hline Age, y & 54.36 & 40 & 54.34 & 32 & .997 \\
\hline Gender & & & & & .428 \\
\hline Male & 50.00 & 20 & 40.63 & 13 & \\
\hline Female & 50.00 & 20 & 59.38 & 19 & \\
\hline Race/ethnicity & & & & & .505 \\
\hline White & 87.50 & 35 & 87.5 & 28 & \\
\hline Black or African American & 5.00 & 2 & 0.00 & 0 & \\
\hline Asian & 5.00 & 2 & 3.12 & 1 & \\
\hline Other & 2.50 & 1 & 9.38 & 3 & \\
\hline Education & & & & & .814 \\
\hline No high school degree & 0.00 & 0 & 0.00 & 0 & \\
\hline High school graduate & 0.00 & 0 & 3.13 & 1 & \\
\hline Some college & 12.50 & 5 & 12.50 & 4 & \\
\hline Associate's degree & 5.00 & 2 & 3.13 & 1 & \\
\hline Bachelor's degree & 27.50 & 11 & 31.25 & 10 & \\
\hline Advanced degree & 55.00 & 22 & 50.00 & 16 & \\
\hline Marital status & & & & & .349 \\
\hline Single & 30.00 & 12 & 21.88 & 7 & \\
\hline Married & 57.50 & 23 & 75.00 & 24 & \\
\hline Widowed & 2.50 & 1 & 0.00 & 0 & \\
\hline Divorced & 10.00 & 4 & 3.13 & 1 & \\
\hline Reason for seeing spine surgeon & & & & & .556 \\
\hline Scoliosis/deformity & 12.82 & 5 & 25.00 & 8 & \\
\hline Cervical issues & 20.51 & 8 & 21.88 & 7 & \\
\hline Lumbar/low back problems & 56.41 & 22 & 46.88 & 15 & \\
\hline Other & 10.26 & 4 & 6.25 & 2 & \\
\hline
\end{tabular}

to determine the total number patients needed to enroll in this study.

\section{Statistical Methods}

The data were analyzed using SPSS. The education intervention group was compared to the nonintervention group using a one-tailed, heterotastic $t$ test with a statistical significance of 0.05 .

\section{RESULTS}

A total of 63 patients who participated in this study, 29 respondents in the intervention group (received the osteoporosis information packet) and 34 in the nonintervention group (did not receive the osteoporosis information packet), completed the survey. Patient demographics of both groups are summarized in Table 1. The average age of the patients was 54.35 , and there were 33 women and 39 men who participated. This patient population consisted of a large proportion of Caucasian $(87.5 \%, \mathrm{n}=63)$, married $(65.3 \%, \mathrm{n}=47)$, and those with a college or advanced degree $(82.0 \%, \mathrm{n}=$ 59). The majority of patients were seeking consultation for lower back/lumbar spine issues $(51 \%, \mathrm{n}=$ $37)$. There were no statistically significant demographic differences between the intervention and nonintervention groups.
Table 2. Patient prior experience with osteoporosis.

\begin{tabular}{|c|c|c|c|c|c|}
\hline & $\begin{array}{c}\text { No } \\
\text { Packet, \% }\end{array}$ & $\mathbf{n}$ & $\begin{array}{c}\text { Packet, } \\
\%\end{array}$ & $\mathbf{n}$ & $\begin{array}{c}P \\
\text { Value }\end{array}$ \\
\hline \multicolumn{5}{|c|}{ Does anyone in your family have a history of osteoporosis? } & .515 \\
\hline Yes & 37.50 & 15 & 34.38 & 11 & \\
\hline No & 40.00 & 16 & 31.25 & 10 & \\
\hline Unsure & 22.50 & 9 & 34.38 & 11 & \\
\hline \multicolumn{5}{|c|}{ Have you ever been diagnosed with osteoporosis? } & .200 \\
\hline Yes & 27.50 & 11 & 15.63 & 5 & \\
\hline No & 62.50 & 25 & 81.25 & 26 & \\
\hline Unsure & 10.00 & 4 & 3.13 & 1 & \\
\hline \multicolumn{6}{|c|}{ How many years has it been since your diagnosis of osteoporosis? } \\
\hline 0 to $3 \mathrm{y}$ & 40.00 & 4 & 60.00 & 3 & \\
\hline 3 to $5 \mathrm{y}$ & 20.00 & 2 & 0.00 & 0 & \\
\hline $5+y$ & 40.00 & 4 & 40.00 & 2 & \\
\hline \multicolumn{5}{|c|}{ Have you ever been diagnosed with a compression fracture? } & .881 \\
\hline Yes & 10.26 & 4 & 12.90 & 4 & \\
\hline No & 84.62 & 33 & 83.87 & 26 & \\
\hline Unsure & 5.13 & 2 & 3.23 & 1 & \\
\hline \multicolumn{5}{|c|}{ Do you currently take osteoporosis medications? } & .470 \\
\hline Yes & 23.08 & 9 & 16.13 & 5 & \\
\hline No & 76.92 & 30 & 83.87 & 26 & \\
\hline Unsure & 0.00 & 0 & 0.00 & 0 & \\
\hline \multicolumn{6}{|c|}{ Which osteoporosis medications do you take } \\
\hline Fosamax (Alendronate) & 12.50 & 1 & 20.00 & 1 & \\
\hline Boniva (Ibandronate) & 0.00 & 0 & 20.00 & 1 & \\
\hline Actonel (Risedronate) & 0.00 & 0 & 0.00 & 0 & \\
\hline Prolia (Denosumab) & 37.50 & 3 & 0.00 & 0 & \\
\hline Forteo (Teriparatide) & 0.00 & 0 & 60.00 & 3 & \\
\hline Other & 50.00 & 4 & 20.00 & 1 & \\
\hline \multicolumn{5}{|c|}{$\begin{array}{l}\text { Have you previously taken medication to treat or prevent } \\
\text { osteoporosis? }\end{array}$} & .709 \\
\hline Yes & 12.50 & 5 & 9.68 & 3 & \\
\hline No & 87.50 & 35 & 90.32 & 28 & \\
\hline Unsure & 0.00 & 0 & 0.00 & 0 & \\
\hline \multicolumn{6}{|c|}{ Which osteoporosis medication did you previously take? } \\
\hline Fosamax (Alendronate) & 20.00 & 1 & 66.67 & 2 & \\
\hline Boniva (Ibandronate) & 40.00 & 2 & 0.00 & 0 & \\
\hline Actonel (Risedronate) & 20.00 & 1 & 33.33 & 1 & \\
\hline Prolia (Denosumab) & 0.00 & 0 & 33.33 & 1 & \\
\hline Forteo (Teriparatide) & 20.00 & 1 & 0.00 & 0 & \\
\hline Other & 60.00 & 3 & 0.00 & 0 & \\
\hline \multicolumn{5}{|c|}{ Have you ever seen a doctor who specializes in osteoporosis? } & .266 \\
\hline Yes & 10.81 & 4 & 12.90 & 4 & \\
\hline No & 81.08 & 30 & 87.10 & 27 & \\
\hline Unsure & 8.11 & 3 & 0.00 & 0 & \\
\hline
\end{tabular}

Patients were also asked a series of questions related to their own osteoporosis health, and these results are summarized in Table 2. This patient population had minimal prior experience with osteoporosis treatment. The majority of patients had never been treated clinically for osteoporosis as follows: $70.8 \%(\mathrm{n}=51)$ of patients had never been diagnosed with osteoporosis, $81.9 \%(n=59)$ of patients had never been diagnosed with a vertebral compression fracture, and 79.2\% $(\mathrm{n}=57)$ of patients had never seen a doctor who specializes in osteoporosis. There were no statistically significant differences between the intervention and nonintervention groups in the areas of prior osteoporosis treatment. 
Table 3. Patient interest in seeing an osteoporosis specialist.

\begin{tabular}{lcrcrr}
\hline & $\begin{array}{c}\text { Packet, } \\
\text { \% }\end{array}$ & n & $\begin{array}{c}\text { No } \\
\text { Packet, } \%\end{array}$ & n & $\begin{array}{c}\boldsymbol{P} \\
\text { Value }\end{array}$ \\
\hline Would you be interested in seeing & orteoporosis specialist? & .068 \\
Definitely yes & 17.95 & 7 & 9.68 & 3 & \\
Probably yes & 20.51 & 8 & 9.68 & 3 & \\
Might or might not & 30.77 & 12 & 32.26 & 10 & \\
Probably not & 20.51 & 8 & 29.03 & 9 & \\
Definitely not & 10.26 & 4 & 19.35 & 6 & \\
Do you think you could benefit from seeing an osteoporosis & .124 \\
$\quad$ specialist? & 12.82 & 5 & 3.23 & 1 & \\
Definitely yes & 25.64 & 10 & 19.35 & 6 & \\
Probably yes & 30.77 & 12 & 32.26 & 10 & \\
Might or might not & 20.51 & 8 & 32.26 & 10 & \\
Probably not & 10.26 & 4 & 12.90 & 4 & \\
Definitely not & & \multicolumn{5}{c}{} \\
\hline
\end{tabular}

Patients who elected to participate were randomly divided into two groups, as shown in Figure 1. Additionally, patients were surveyed about their willingness to see an osteoporosis specialist. The results are summarized in Table 3. Despite most of these patients having no prior experience with osteoporosis, $59.7 \%(\mathrm{n}=43)$ were either interested in or open to the idea of seeing an osteoporosis specialist, and $61.1 \%(n=44)$ felt that there may be a benefit from seeing an osteoporosis specialist. There were no statistically significant differences in the response to these questions between the intervention group and the nonintervention group.

The average FOOQ scores for the information packet and non-information packet groups were evaluated. The mean FOOQ score for the patients who were given the information packet prior to answering the survey was 16.37 ( \pm 2.35 ), or a score of $82 \%$. The mean FOOQ score for patients who did not receive the information packet was 15.62 $( \pm 2.87$ ), or a score of $78 \%$. This score difference was not statistically significant with a $P$ value of .12 . These results are summarized in Table 4 and Figure 2.

\section{DISCUSSION}

With increasing utilization of spine surgery by older patients with osteoporosis, the need to understand the typical spine patient's knowledge

Table 4. Facts on Osteoporosis Quiz scores.

\begin{tabular}{lcccccc}
\hline & n & Mean & SD & Variance & $\begin{array}{c}\text { Confidence } \\
\text { Interval }\end{array}$ & $\boldsymbol{P}$ Value \\
\hline With packet & 29 & 16.38 & 2.35 & 5.53 & $15.48-17.27$ & .12 \\
Without packet & 34 & 15.62 & 2.87 & 8.24 & $14.62-16.62$ & \\
\hline
\end{tabular}

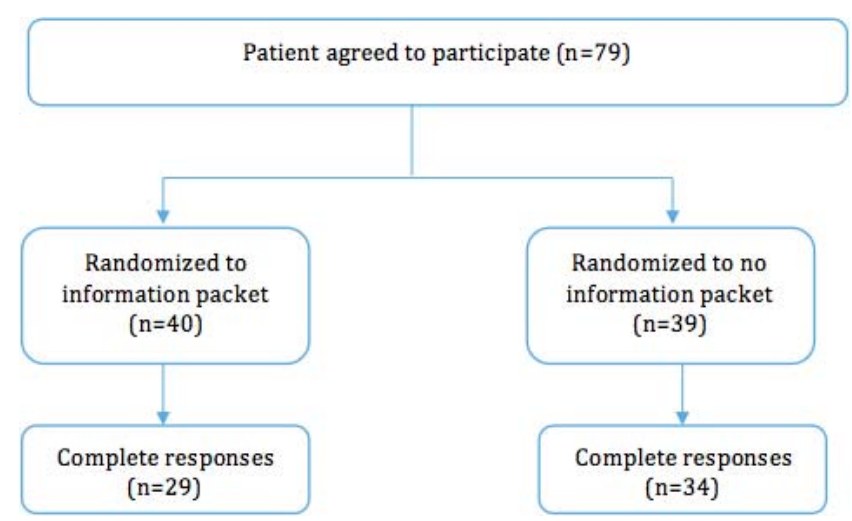

Figure 1. Study design flowchart. This flowchart demonstrates patient randomization into information packet or no information packet prior to receiving the Facts on Osteoporosis Quiz.

of osteoporosis becomes increasingly important, particularly in the quest to improve and optimize spine surgery outcomes.

Prior studies using the FOOQ to evaluate patient knowledge of osteoporosis have reported lower scores than we saw among both groups surveyed in our analysis. A 1998 study of 247 women found a mean FOOQ score of $64 \%$, significantly higher than the $78 \%$ reported for our control group and $82 \%$ for the group given the information packet. ${ }^{12}$ With over $80 \%$ of all respondents having a bachelor's degree or higher, it could be assumed that the higher FOOQ scores in our study are due to a high patient educational level. Initial studies utilizing the FOOQ demonstrated minimal correlation between years of educational attainment and osteoporosis knowledge. ${ }^{10,11}$ Instead, the only factor associated with increased FOOQ scores was prior exposure to osteoporosis knowledge materials or teaching. Since the time of these initial studies, considerable public

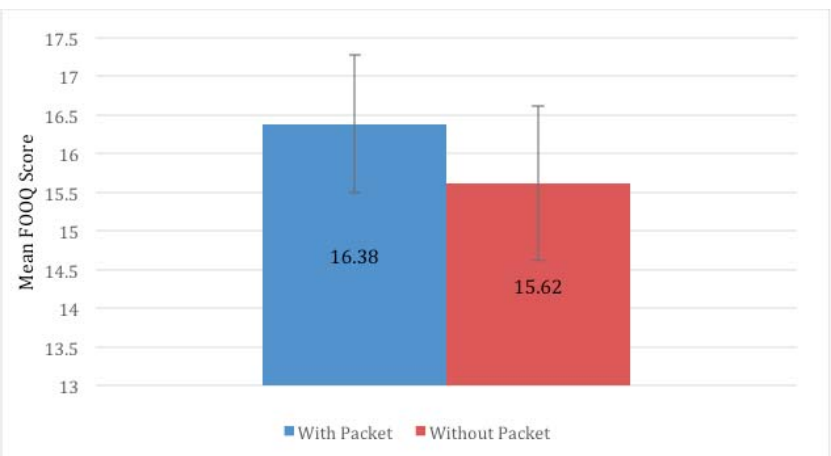

Figure 2. Facts on Osteoporosis Quiz scores. This chart demonstrates the mean score on the Facts on Osteoporosis Quiz for the information packet and non-information packet patient groups. The bar represents the standard deviation for the mean score. 
and community health resources have been allocated with the explicit goal of improving osteoporosis knowledge, particularly among at-risk groups, such as postmenopausal women. ${ }^{13,14}$ We posit that it is possible that general public knowledge of osteoporosis has increased since the original publication of the FOOQ instrument. As such, the current level of osteoporosis knowledge in the general population is higher.

Additionally, there are no studies that have established osteoporosis knowledge among spine surgery patients in particular. Spine surgeons are often secondary or tertiary care providers. It is likely that patients coming to see a spine surgeon for the first time have already consulted a general physician and possibly a general orthopedic surgeon. Each of these prior visits provides the opportunity for osteoporosis education, and by the time they see a spine surgeon, the typical patient has had some exposure to osteoporosis education.

Our study did not find a statistically significant difference in FOOQ scores between those patients who received the educational pamphlet and those who did not. Our initial hypothesis was that a brief subject-based intervention would result in higher FOOQ scores. Our sample size was based on a power analysis, but there is a small chance that a larger sample size would have shown a difference in FOOQ scores between the study groups.

One limitation of the study was the design of the educational information packet. Patients were allowed to spend as much time as they chose with the brief information packet; time stamps indicate that, on average, over $80 \%$ of patients spent less than 5 minutes on the survey in total. This indicates that patients skimmed through the information packet. Beyond this, patients were given only one opportunity to browse the information packet. As such, they were not exposed to educational information on multiple occasions, as might have been preferred in a study of longer duration. While an information packet provides an easy, highly reproducible, and very cheaply distributable method of increasing osteoporosis knowledge, lack of patient engagement with the packet likely limited the educational impact. Prior studies have shown that education leaflets have a limited efficacy. ${ }^{15}$

\section{CONCLUSION}

In summary, this study provides a more detailed look into the knowledge and attitudes patients have about osteoporosis when consulting a spine surgeon for the first time. Patients in our samples showed higher-than-average FOOQ scores and were willing and open to see osteoporosis specialists should they require such care. While the information packet intervention did not result in statistically significant differences in osteoporosis knowledge in both groups, our results demonstrate the high level of knowledge that spine surgery patients have regarding osteoporosis. This demonstrates that discussing osteoporosis treatment as part of the spine treatment is a reasonable task for spine surgeons.

\section{REFERENCES}

1. Hall MJ, DeFrances CJ, Williams SN, Gologsinskiy A, Schwartzman A. National Hospital Discharge Survey: 2007 summary. Natl Health Status Rep. 2010;29(29):1-20.

2. Chin D, Park JY, Yoon YS, et al. Prevalence of osteoporosis in patients requiring spine surgery: incidence and significance of osteoporosis in spine disease. Osteoporos Int. 2007;18(9):1219-1224.

3. DeWald CJ, Stanley T. Instrumentation-related complications of multilevel fusions for adult spinal deformity patients over age 65: surgical considerations and treatment options in patients with poor bone quality. Spine (Phila Pa 1976). 2006;31(19S):S144-S151.

4. Halvorson TL, Kelley LA, Thomas KA, Whitecloud TS 3rd, Cook SD. Effects of bone mineral density on pedicle screw fixation. Spine (Phila Pa 1976). 1994;19(21):2415-2420.

5. O'Loughlin PF, Cunningham ME, Bukata SV, et al. Parathyroid hormone (1-34) augments spinal fusion, fusion mass volume, and fusion mass quality in a rabbit spinal fusion model. Spine (Phila Pa 1976). 2009;34(2):121-130.

6. Ohtori $\mathrm{S}$, Inoue $\mathrm{G}$, Orita $\mathrm{S}$, et al. Comparison of teriparatide and bisphosphonate treatment to reduce pedicle screw loosening after lumbar spinal fusion surgery in postmenopausal women with osteoporosis from a bone quality perspective. Spine (Phila Pa 1976). 2013;38(8):E487-E492.

7. Sugiura T, Kashii M, Matsuo $\mathrm{Y}$, et al. Intermittent administration of teriparatide enhances graft bone healing and accelerates spinal fusion in rats with glucocorticoid-induced osteoporosis. Spine J. 2015;15(2):298-306.

8. Office of the Surgeon General. Bone Health and Osteoporosis: A Report of the Surgeon General. Rockville, MD: US Department of Health and Human Services, Office of the Surgeon General; 2004.

9. Dell RM, Greene D, Anderson D, Williams K. Osteoporosis disease management: what every orthopaedic surgeon should know. J Bone Joint Surg Am. 2009;91(suppl 6):79-86.

10. Ailinger RL, Harper DC, Lasus HA. Bone up on osteoporosis: development of the Facts on Osteoporosis Quiz. Orthop Nurs. 1998;17(5):66-73.

11. Ailinger RL, Lasus H, Braun MA. Revision of the Facts on Osteoporosis Quiz. Nurs Res. 2003;52(3):198-201.

12. Ailinger RL, Emerson J. Women's knowledge of osteoporosis. Appl Nurs Res. 1998;11(3):111-114.

13. Francis K, Matthews BL, Van Mechelen W, Bennell KL, 
Osborne RH. Effectiveness of a community-based osteoporosis education and self-management course: a wait list controlled trial. Osteoporos Int. 2009;20(9):1563-1570.

14. Tussing L, Chapman-Novakofski K. Osteoporosis prevention education: behavior theories and calcium intake. $J$ Am Diet Assoc. 2005;105(1):92-97.

15. Guilera M, Fuentes M, Grifols M, Ferrer J, Badia X; OPTIMA Study Investigators. Does an educational leaflet improve self-reported adherence to therapy in osteoporosis? The OPTIMA study. Osteoporos Int. 2006;17(5):664-671.

Disclosures and COI: The authors declare no potential conflicts of interest with respect to the research, authorship, and/or publication of this article. Permission to reproduce copyrighted work: there is no copyrighted work in this manuscript. Institutional review board approval was obtained prior to starting this research. The authors received no financial support for the research, authorship, and/or publication of this article.

Corresponding Author: Charla Fischer, 246 East 20th Street, New York, NY 10003. Phone: (646) 356-9415; Fax: (646) 356-9413; Email: Charla. fischer@nyumc.org.

Published 21 December 2018

This manuscript is generously published free of charge by ISASS, the International Society for the Advancement of Spine Surgery. Copyright (c) 2018 ISASS. To see more or order reprints or permissions, see http://ijssurgery.com. 